\title{
Craniofacial morphometric study of adult Ogoni people of Nigeria
}

\begin{abstract}
Craniofacial anthropometry requires series of direct standard anthropometric measurement of the bones of the human skull. The study was aimed at establishing baseline data of the craniofacial parameters which are head circumference, intercanthal distances, canthal index and circumference interorbital index of the adult Ogonis of Nigeria. A total of three hundred and eighty two (382) subjects were selected randomly from Kibagha in Gokana local government area, Bori in Khana local government area, Nonwa in Tai local government area and Alesa in Eleme local government area all in Ogoni. Three hundred and eighty two (382) subjects which include one hundred and eighty nine (189) and one hundred and ninety three (193) for males and females respectively with a non-stretchable plastic ruler with $0.5 \mathrm{~cm}$ interval was used for the measurement and the data. The results showed among others, the mean age value as $30.81 \pm 10.13$ for male and $32.64 \pm 10.91$ for female, head circumference (male $56.41 \pm 1.52 \mathrm{~cm}$, female $57.05 \pm 2.02 \mathrm{~cm}$ ), intercanthal distance (male $3.56 \pm 0.30 \mathrm{~cm}$, female $3.47 \pm 0.26$ ), outer canthal distance (male $12.53 \pm 0.49 \mathrm{~cm}$, female $12.39 \pm 0.55 \mathrm{~cm}$ ), canthal index (male $28.41 \pm 1.79 \mathrm{~cm}$, female $28.15 \pm 1.83 \mathrm{~cm}$ ) and circumference inter-orbital index (male $6.31 \pm 0.44 \mathrm{~cm}$, female $6.09 \pm 0.40 \mathrm{~cm}$ ). It showed statistical significant difference between the male and female among the parameters measured indicating sexual dimorphism. Discriminate function analysis of Wilkis' Lambda test also confirms accurateness and predictability of the statistical significant difference of male and female measured variables. The knowledge from the study can provide information for craniofacial assessment for important clinical questions in research especially during surgery on the cranium development forensic investigation in personal identification in the population and society at large.
\end{abstract}

Keywords: head circumference, inner canthal distance, outer canthal distance, canthal index, circumference interorbital index
Volume 5 Issue 5 - 2018

\author{
Oladipo GS,' Uzomba GC, ${ }^{2}$ Alabi AS, ${ }^{3}$ \\ Gbarayege BB' \\ 'Department of Anatomy, University of Port Harcourt, Nigeria \\ ${ }^{2}$ Department of Anatomy, Federal University, Nigeria \\ ${ }^{3}$ Department of Anatomy, University of Ilorin, Nigeria
}

Correspondence: Uzomba GC, Department of Anatomy, Federal University, NdufuAlikelkwo, Ebonyi State, Tel

+234806 I I 50454, Nigeria, Email uzamba.godwin@funai.edu.ng

Received: July 28, 2018 | Published: October 17, 2018

\section{Introduction}

Craniofacial morphometric study is a constituent of both cranial and facial parameters such as fronto-occipital circumference, intercanthal distance, canthal index and circumference interorbital index and over the years they have showed consistent important landmark for anatomist and surgeons. In the view of ${ }^{1}$ craniofacial anthropometry is a technique used in bothphysical and clinical anthropology comprising precise and systematic measurements of the bones of the human skull.The usefulness of head circumference, intercanthal distances, canthal index and circumference interorbital index to clinicians in description diagnosis and surgical treatment of abnormal skeletal and facial patternsand manufacturing of spectacle frames and lenses cannot be overemphasized ${ }^{2}$ and their also reported the male mean canthal indices of Ijaw and Igbo tribes of Nigeria to be 37.04 and 32.59 respectively and female Ijaw as 33.11 and female Igbo as 32.51 .

The mean result of the comparative study carried out by Oladipo et al., ${ }^{3}$ revealed male Ijaws 37.04 and Igbo 35.15. Face is appearance and description of an attractive of personality, culture, age, ethnic background as well as personal preferences. ${ }^{4}$ Scholars in Nigeria have documented the baseline data of studied anthropometric parameters in Ethnic groups of Nigeria, however, none could be attributed to Ogoni ethnic group, thus, the study aimed at establishing baseline data of the craniofacial parameters which are head circumference, intercanthal distances, canthal index and circumference interorbital index of the adult Ogonis of Nigeria and documenting standard values with available data from other ethnic groups and other populations of the world for any ethnic or racial differences which would be very useful in anthropological studies, craniofacial surgery, diagnosis of craniofacial anormalies and forensic medicine.

\section{Materials and methods}

This study was carried out on Ogoni Ethnic group of Rivers State. A total of three hundred and eighty two (382) subjects were selected randomly from Kibagha in Gokana local government area, Bori in Khana local government area, Nonwa in Tai local government area and Alesa in Eleme local government area all in Ogoni. Three hundred and eighty two (382) subjects which include one hundred and eighty nine 189) and one hundred and ninety three (193) for males and females respectively. Subjects with any craniofacial deformity were not selected. The method adopted for assessing the Canthal Index was ${ }^{5}$ while the circumference inter - orbital index was. ${ }^{6}$ A non-stretchable plastic ruler with $0.5 \mathrm{~cm}$ interval was used for the measurement and the data were subjected to analysis using SPSS version 20.0.

\section{Result}

Table 1 Summarize descriptive statistics of age, head circumference (HC), intercanthal distance (ICD), outer canthal distance (OCD), canthal index (CI) and circumference inter-orbital index (CI-I) in both male and female of Ogonis.the mean results revealed as follows: age (male $30.81 \pm 10.13 \mathrm{~cm}$, female $32.64 \pm 10.91 \mathrm{~cm}$ ), head circumference 
(male $56.41 \pm 1.52 \mathrm{~cm}$, female $57.05 \pm 2.02 \mathrm{~cm}$ ), intercanthal distance (male $3.56 \pm 0.30 \mathrm{~cm}$, female $3.47 \pm 0.26$ ), outer canthal distance (male $12.53 \pm 0.49 \mathrm{~cm}$, female $12.39 \pm 0.55 \mathrm{~cm}$ ), canthal index (male
$28.41 \pm 1.79 \mathrm{~cm}$, female $28.15 \pm 1.83 \mathrm{~cm}$ ) and circumference inter-orbital index (male $6.31 \pm 0.44 \mathrm{~cm}$, female $6.09 \pm 0.40 \mathrm{~cm}$ ).

Table I Summary of the descriptive statistics of age, $\mathrm{HC}$, head circumference; ICD, intercanthal distance; $\mathrm{OCD}$, outer canthal distance; $\mathrm{Cl}$, canthal index; and circumference inter-orbital index $(\mathrm{Cl}-\mathrm{I})$ in male and female of Ogonis

\begin{tabular}{lllllllll}
\hline & \multicolumn{2}{l}{ Sample Size } & \multicolumn{2}{l}{ Minimum value } & \multicolumn{2}{l}{ Maximum value } & \multicolumn{2}{l}{ Mean \pm SD } \\
\cline { 2 - 8 } Variables & Male & Female & Male & Female & Male & Female & Male & Female \\
\hline Age (years) & 189 & 193 & 18 & 18 & 70 & 62 & $30.81 \pm 10.13$ & $32.64 \pm 10.91$ \\
$\mathrm{HC}(\mathrm{cm})$ & 189 & 193 & 52.1 & 52.2 & 59.5 & 62.5 & $56.41 \pm 1.52$ & $57.05 \pm 2.02$ \\
$\mathrm{ICD}(\mathrm{cm})$ & 189 & 193 & 2.9 & 2.9 & 4.5 & 4.2 & $3.56 \pm 0.30$ & $3.47 \pm 0.26$ \\
$\mathrm{OCD}(\mathrm{cm})$ & 189 & 193 & 11.4 & 10.8 & 14.2 & 14.5 & $12.53 \pm 0.49$ & $12.39 \pm 0.55$ \\
$\mathrm{Cl}$ & 189 & 193 & 24.59 & 24 & 33.6 & 38.8 & $28.41 \pm 1.79$ & $28.15 \pm 1.83$ \\
$\mathrm{Cl}-\mathrm{I}$ & 189 & 193 & 5.3 & 5.1 & 7.73 & 7.16 & $6.31 \pm 0.44$ & $6.09 \pm 0.40$ \\
\hline
\end{tabular}

Table 2 showed the results of paired sample Test (z-test) of parameters or variables in male and female Ogonis at confidence interval of $95 \% \quad(\mathrm{P}=0.05)$. from the results, it is evidence that the craniofacial parameters of male and female of Ogonis were significance different and showed sexual dimorphic incraniofacial parameters in both male and female Ogoni at alpha significant level of 0.05 . Tables 3A \& 3B showed comparative data of canthal indices and circumference inter-orbial index in of Nigerian ethnic and subethnic groups and other foreign populations. In Table 4, discriminate function analysis of Wilkis' Lambda test was used for predictability into group membership of male and female craniofacial parameters. It further revealed that all the predictors add certain predictive power to the discriminate functions showed significant difference at $\mathrm{P}<0.001$

Table 2 Results of paired sample Test (z-test) of craniofacial parameters in male and female Ogonis at confidence interval of $95 \%(P=0.05)$

\begin{tabular}{lllll}
\hline Variables & P-values & Degree of freedom & z-values (t-calculated) & Inference \\
\hline Age & 0.069 & 188 & 1.83 & Significant (2-tailed) \\
$\mathrm{HC}$ & 0 & 188 & 3.678 & Significant (2-tailed) \\
$\mathrm{ICD}$ & 0.003 & 188 & 2.99 & Significant (2-tailed) \\
$\mathrm{OCD}$ & 0.008 & 188 & 2.674 & Significant (2-tailed) \\
$\mathrm{Cl}$ & 0.183 & 188 & 1.337 & Significant (2-tailed) \\
$\mathrm{Cl}-\mathrm{I}$ & 0 & 188 & 4.906 & Significant (2-tailed) \\
\hline
\end{tabular}

Table 3A A comparison of Canthal Index in male and female Ogonis and other Nigerian Populations previously studied

\begin{tabular}{llll}
\hline Authors/years & Population & Male & Female \\
\hline Oladipo et al. & Bayelsa & $30.01 \pm .1 .33$ & $30.01 \pm .1 .07$ \\
Nzeakor et al. ${ }^{8}$ & Ika North and South & $30.93 \pm 3.30$ & $30.73 \pm 2.87$ \\
Dennis et al. ${ }^{9}$ & Urhobo & $37.12 \pm 2.78$ & $36.84 \pm 2.60$ \\
Oladipo et al. ${ }^{10}$ & Ibiobio & $31.64 \pm 2.57$ & $31.47 \pm 4.62$ \\
Oladipo et al. ${ }^{11}$ & Igbo & 35.15 & 32.59 \\
Egwu et al. ${ }^{12}$ & Igbo & $37.10 \pm 2.93$ & $36.41 \pm 2.69$ \\
Oladipo et al. ${ }^{3}$ & Urhobo & $24.38 \pm 1.96$ & $29.38 \pm 1.37$ \\
\hline Present study & Ogonis & $26.03 \pm 1.46$ & $27.7 \pm 1.35$ \\
\hline
\end{tabular}

Table 3B A comparison of circumference inter-orbital index in male and female Ogonis and other Nigerian Populations previously studied

\begin{tabular}{llll}
\hline Authors/years & Population & Male & Female \\
\hline Dennis et al. ${ }^{9}$ & Urhobo & $7.15 \pm 0.74$ & $7.12 \pm 0.68$ \\
Chukwujekwuet al. ${ }^{13}$ & lgbos & $10.62 \pm 0.61$ & $10.49 \pm 0.74$ \\
Aniboret al. ${ }^{14}$ & Isoko & $6.62 \pm 0.38$ & $6.58 \pm 0.10$ \\
Oladipoet al. & ljaw & $7.80 \pm 2.20$ & $8.10 \pm 0.60$ \\
& lgbos & $6.20 \pm 0.50$ & $6.50 \pm 0.20$ \\
Oladipoet al. ${ }^{15}$ & $\begin{array}{l}\text { Southern } \\
\text { Nigeria }\end{array}$ & $6.03 \pm 6.53$ & $6.50 \pm 0.36$ \\
Present study & Ogonis & $6.31 \pm 0.44$ & $6.09 \pm 0.40$ \\
\hline
\end{tabular}


Table 4 Discriminate function analysis of Wilkis' Lambda test for predictability into group membership

\begin{tabular}{llllll}
\hline Wilks' Lambda & & & & & \\
\hline Test of Function(s) & Wilks' Lambda & Chi-square & df & Sig. & Remarks \\
\hline Canthal Index & 0.984 & 5.997 & I & 0.014 & Significant \\
C.I.I & 0.933 & 26.171 & I & 0 & Significant \\
\hline
\end{tabular}

\section{Discussion}

Craniofacial anthropometry requires series of direct standard anthropometric measurement of the bones of the human skull. The present study provided a baseline information of craniofacial anthropometry of male and female of Ogonis with respect to their mean values of head circumference, intercanthal distances, outer canthal distance, canthal index and circumference interorbital index. The presence of sexual dimorphism in this study agreed with other studies that compared craniofacial characteristics of male and female and also showed significant difference in the craniofacial parameters of male and female Ogonis at the significant level of $\mathrm{P}=0.05$.

From the result of the present study, the canthal index of the female mean is similar with work done by Oladipo et al., ${ }^{3}$ on female Itsekiri who reported the mean value as $27.7 \pm 1.35$, however, it is not in agreement with the research work done by Oladipo et al., ${ }^{3}$ on male Urhobo and Itsekiri who documented their values as $24.38 \pm 1.96$ and $26.03 \pm 1.46$ respectively. It also differed with the work done by Oladipo et al., ${ }^{7}$ who have the mean values of Bayelsans as $30.01 \pm 1.33$ for male and $30.01 \pm 1.07$ for female. In line with this, Nzeakoret al., documented the mean values of Ika North and South male (30.93 \pm 3.30$)$ and female (30.73 \pm 2.87$)$. This research did not concur with the work done by Dennis et al., ${ }^{9}$ on the male and female Urhobo population as their values were (male $37.12 \pm 2.78$ and female $36.84 \pm 2.60$ ). ${ }^{10,11}$ Igbo population also presented the highest value in canthal index (37.10 \pm 2.93 for male and $36.41 \pm 2.69$ for female)..$^{12-14}$

The result of circumference interorbital index showed similar with the work carried out by Oladipo et al., ${ }^{3}$ on Igbos who documented their mean values as (male 6.20 0.50 and female $6.50 \pm 0.20$ ). Another research study done by Oladipo et al., ${ }^{15}$ on the Southern Nigeria with the male and female values of $6.30 \pm 6.53$ and $6.50 \pm 0.36$ respectively also agreed with the present study. The present study also agreed with the research investigation done by Anibor on the male and female Isoko population which has the mean values of male as $6.62 \pm 0.38$ and female as $6.58 \pm 0.10$. Conversely, the present disagreed with the done by Dennis et al., ${ }^{9}$ on the Urhobo population as (male 7.15 \pm 0.74 and female $7.12 \pm 0.68$ ) and Chukwujekwu et al., ${ }^{13}$ on Igbo population which has their values of male and female as $10.62 \pm 0.62$ and $10.49 \pm 0.74$ respectively. Research work done by Oladipo et al., ${ }^{3}$ on Ijaws also did not agree with the present study.

Discriminate function analysis of Wilkis' Lambda test was used for predictability into group membership of male and female craniofacial parameters. It revealed that all the predictors add certain predictive power to the discriminate functions showed significant difference at $\mathrm{P}<0.001$, which confirms accurateness and predictability of the statistical significant difference of male and female measured variables.

\section{Conclusion}

The present study has established baseline information for male and female craniofacial parameters of Ogonis which may serve as useful source for preliminary identification purposes especially in settings that encourage forensic investigation. The variation in this study could be accrued to genetics and environmental factors within and between populations. The findings of this study, therefore has the ability for provision of craniofacial assessment, helps to provide important clinical questions in research especially during surgery on the cranium development, it would also provide forensic investigation in personal identification in the population and society at large.

\section{Acknowledgements}

None.

\section{Conflict of interest}

The author declares no conflict of interest.

\section{References}

1. Mahfouz KJ. Craniofacial anthropometry of a group of Resident of New Delhi in India. 1988;33:243-247.

2. Oladipo GS, Yorkum LS, Okoh P. Measurements of Head Circumference, Intercanthal Distances, Canthal Index and Circumference Interorbital Index of Ikwerre School Children in Nigeria. Journal of Natural Science Research. 2013;3(4):16-20.

3. Oladipo GS, Ugboma A, Oyakhire M. The circumference Interorbital index of Ijaw and Igbo ethnic groups in Nigeria. Int $J$ Biol Anthropol. 2008;3(2)

4. Didia BC, Dapper DV. Facial, Nasal, Maxillary, Mandibular and Orofacial heights of adult Nigerians. Orient J Med. 2005;17:1-8.

5. Williams PL, Bannister LH, Dyson M, et al. Gray's Anatomy. 38th ed. Edinburgh, London: Churchill Livingstone; 1995. p. 609-12.

6. Anderson AL. Accurate clinical means of measuring intervisual axis distance. Arch Ophthamol. 1954;52(3):349-352.

7. Oladipo GS, Ipigansi UN, Alabi AS, et al. Measurements of Head Circumference, Intercanthal Distances, Canthal Index and Circumference Interorbital Index of Children and Adolescents in Bayelsa State in Nigeria. World J Pharmaceu Res. 2017;6:207-218.

8. Nzeako HC, Emegoakor CD, Ezejindu DN, et al. Anthropometric Variations Of The Inner And Outer Canthal Distances Between Adult Male And Female In Ika North And South Local Government Of Delta State. Cibtech J Bio-Protocols. 2017;6:1-5.

9. Dennis EO, Eboh EO, Ogbor-Omorie, et al. Anthropometric study of canthal and circumference interorbital indices among young Urhobo adults in South-South Nigeria. Annals of Bioanthropol. 2015;3(2):42-46.

10. Oladipo GS, Akande PA, Osogba IG, et al. Anthropometric studies of inner canthal distance, outer canthal distance and canthal index of adult ibibios. Asian J Med Sci. 2011;3:14-16.

11. Oladipo GS, Fawehinmi HB, Suleiman YA. The study of nasal parameters (nasal height, width and nasal index) among the Yorubas of Nigeria. Int J Biol Anthropol. 2009;3:1-19. 
12. Egwu OA, Ewunonu EO, Eteudo AN, et al. Normal values of inner and outer intercanthal distances in a student population in southeast Nigeria. Int J Bio Chem Sci. 2008;2(3):355-358.

13. Chukwujekwu IE, Ezejindu DN, Aduwenye OI. Study of head circumference inter orbital index between the ages of 19-29years of Igbo Tribes in Otolo, Okofia, Nnewi, Anambra State, Nigeria. Int J Res. 2014;1:239-244.
14. Anibor E, Omokaro E, Ofere F. Variations In Canthal Index Of The Isokos In Delta State. Int J Basic Appl Inno Res. 2014;3(4):143-146.

15. Oladipo GS, Okoh PD Hart JS. Anthropometric study of Ocular Dimension in Adult Ijaws of Nigeria. Res J Med Med Sci. 2010;5:121124. 